\title{
NONCONVENTIONAL PRINCIPLE OF CONVERSION OF HEAT INTO COLD IN AN INTERNAL COMBUSTION ENGINE
}

The paper presents results achieved by a team of 12 researchers from the Faculty of Mechanical Engineering of the University of Žilina who participated in the solution of the project of the above-mentioned title within the period of the years $2002-2005$. The basic research project focuses on the cooling internal combustion engine as an element of qualitatively new equipment designed for more effective utilization of fuel energy by a nonconventional progressive principle of heat conversion cooled by thermocompression. The issue of permanently sustainable life is approached from three hierarchical levels: a first level is a cooling internal combustion engine; a second level is a combined cogeneration complex power source; and a third level is a permanently sustainable power system. The cooling internal combustion engine is actually the basic element of the subsystem in the three-level complex of permanently sustainable life. It is still necessary to verify expected advantages of this unconventional combustion engine, potential savings of primary energy and foresee possible problems arisen during the simulation of the engine.

\section{The project objective}

The project objective is to carry out basic research into the fundamentals of a cooling combustion engine designed for more effective utilization of fuel primary energy by means of a nonconventional progressive principle of conversion of heat into cold through thermocompression. The subject of basic research is a nonconventional cooling combustion engine reciprocal movement of the piston and discontinuous combustion examined from the point of view of:

a) theoretical analysis,

b) consecutive mathematical modelling of thermodynamic and energetic states of the cooling combustion engine (taking into consideration the fact that it is the "cooling" engine),

c) selection of components and media focusing on the increase of cooling output generated by the cooling combustion engine and on decrease of thermal losses.

All the above mentioned activities require a flow simulation of the coolant in the engine cooling system as a component of the absorptive cooling circuit with its analysis and consequent synthesis with the objective of designing a suitable configuration of the absorptive cooling circuit and suitable choice of coolant. To determine the data necessary for a mathematical modelling and subsequent verification of calculations and selection of components and coolants it is required:

a) to design a testing model of the cooling combustion engine and for this purpose to accommodate the existing testing stand of the combustion engine,

b) to carry out some experiments.

Expected social benefits are as follows:

- extension of existing knowledge, dissemination of new knowledge - internationally oriented,
- application of new knowledge into teaching materials of institutions of higher learning - professionally oriented,

- transfer of knowledge into solutions of other applied reasearch tasks - specifically oriented,

- enrichment of scientific and technical know how - specifically oriented aspect of solution.

\section{Results of solution}

The assessment is carried out chronologically in relation to the given objectives.

The year 2002

The following activities were carried out:

1. theoretical analysis and mathematical modelling

2. testing stand - reconstruction.

To determine thermal flows from the individual chambers of inserted cylinders it is necessary to know mass flows around the cylinders and temperatures in the corresponding places. This can be solved by a method of composition of the cooling system hydrodynamic elements characteristics. The dependence of specific energy on the mass flow in the cooling circuit can be described by the following set of equations:

$$
\begin{aligned}
& Y_{a}=k_{1 a} \cdot m_{w a}, \\
& Y_{b}=Y_{a b}+k_{1 b} m_{w b}, \\
& Y_{c}=k_{1 c} \cdot m_{w c},
\end{aligned}
$$

\footnotetext{
* Vladimír Hlavňa, Dušan Sojčák, Rastislav Isteník

Faculty of Mechanical Engineering, University of Žilina, Univerzitná 1, 01026 Žilina, Slovakia,

E-mail: Vladimir.Hlavna@fstroj.utc.sk, Dusan.Sojcak@fstroj.utc.sk; Rasto.Istenik@fstroj.utc.sk
} 
$Y_{d}=k_{1 d} \cdot m_{w d}$,

$Y_{e}=Y_{c d}+k_{1 e} \cdot m_{w e}$,

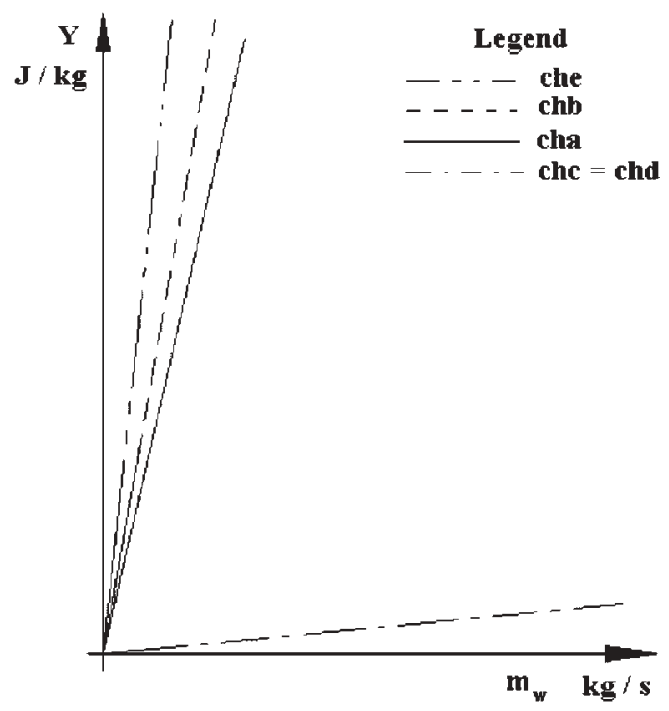

Fig. 1(left) Characteristics of the cooling system: che - characteristics of collector pipe, thermostat and radiator, chb - characteristic of cylinders and cavities around the cylinders, cha - entry of cylinder blocks, chc - characteristics of partitions around cylinders, chd - exit from cylinder heads.

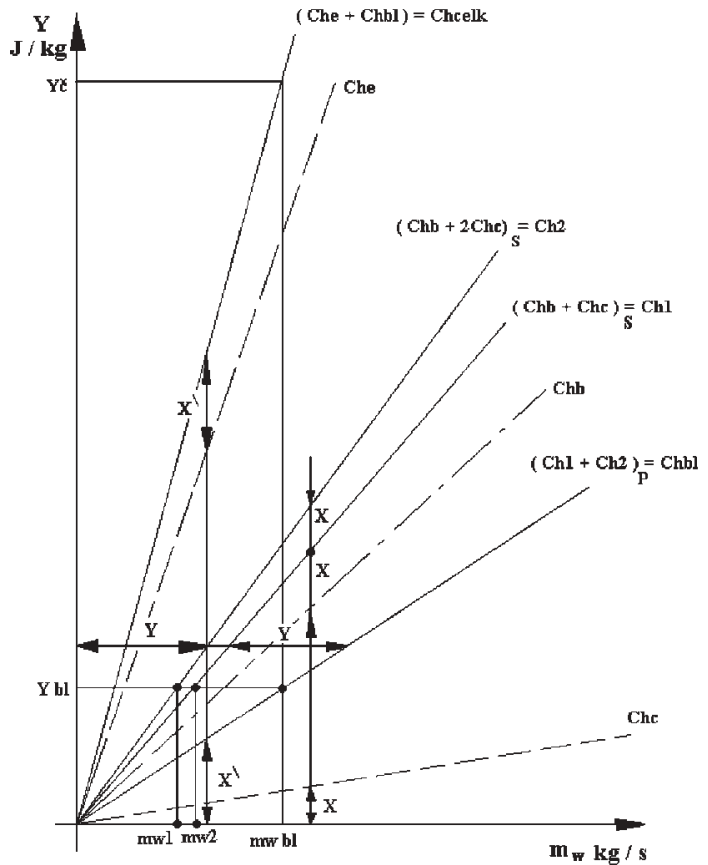

Fig. 2(right) Chbl - characteristic of the block, Ch1 and Ch2 characteristics of cylinders, Chcelk - overall characteristic, Yč - pump specific energy, $\boldsymbol{m} \boldsymbol{w} \boldsymbol{b l}$ - flow in the block, $\boldsymbol{m} \boldsymbol{w} \mathbf{2}$ - flow around the second cylinder, $\mathbf{Y b l}$ - specific energy of the block, Che - characteristics of the collector pipe, thermostat and radiator.
The resultant characteristic of the systems is given by the composition of individual characteristics of elements from Fig. 1, where the series connected elements are summed at a constant mass flow, the parallel connected elements are summed at a constant specific energy, Fig. 2.

Thermal flows from the individual chambers of inserted cylinders can be defined by means of the following equations:

$$
\begin{aligned}
& Q_{i c h}=Q_{i h}+Q_{i w} \\
& Q_{i h}=m_{i h} \cdot c_{i w} \cdot\left(t_{i h}-t_{i+1, w}\right) \\
& Q_{i w}=m_{i w} \cdot c_{i w} \cdot\left(t_{i w}-t_{i+1, w}\right) \\
& m_{i-1, w}=m_{i h}+m_{i w}
\end{aligned}
$$

\section{The year 2003}

The following activities were carried out:

1. theoretical analysis and mathematical modelling:

- A theoretical diagram of cycle was completed and physical and chemical properties $\mathrm{LiBr}-\mathrm{H}_{2} \mathrm{O}$ were found out.

- Modelling and calculation of the inserted cylinder deformation.

- The issue of bubble formation on the surface of the inserted cylinder was solved.

- Modelling and simulation of flows of coolant and energetic flows.

- The project - updating of programme of experiment automation - completed.

- Specification of measurement places.

- Design of measurement chain - sensors, transmitters, ...

2. testing stand

- Methodology of measurement was prepared.

- Cooling circuit - design of arrangement, constructional design of an expansion container and engine adjustment, external pump, sent to a manufacturer, purchases.

- Provision of the external pump and purchase of fuels.

- Constructional design of the expansion container.

- Reconstruction of the testing stand, arrangement of the original measurement chain for measurement with the help of $\mathrm{LiBr}$.

3. experiments

- Measurement of the engine surface temperatures - evaluation.

- Tests of the original engine - measurements of coolant flows.

- Mapping of the engine: characteristics, surface temperatures for two coolants (water, $\mathrm{LiBr}$ ), assessment.

There was no agressive harm or damage of sample material, i.e. neither etching nor dissolving observed.

The following activities were carried out:

- Modelling and computation of the inserted cylinder deformation. 


\section{kOMNIKCCle}

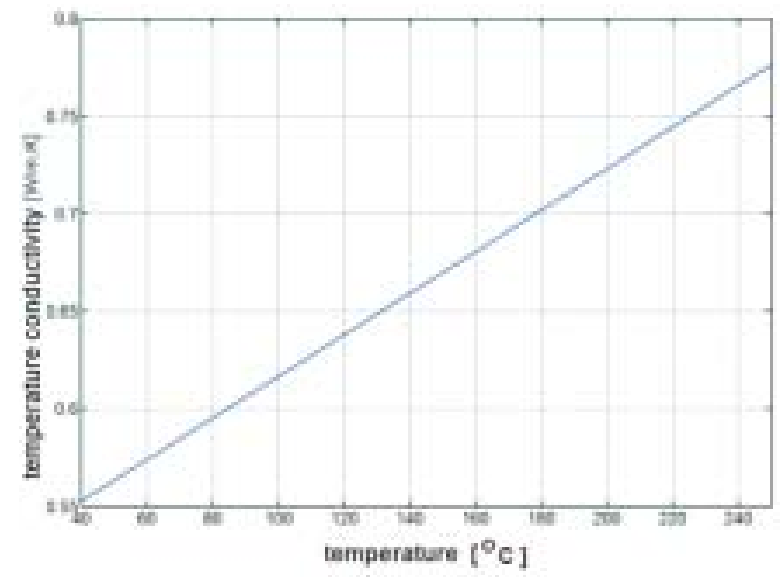

Graph 1 Thermal conductivity of coolant

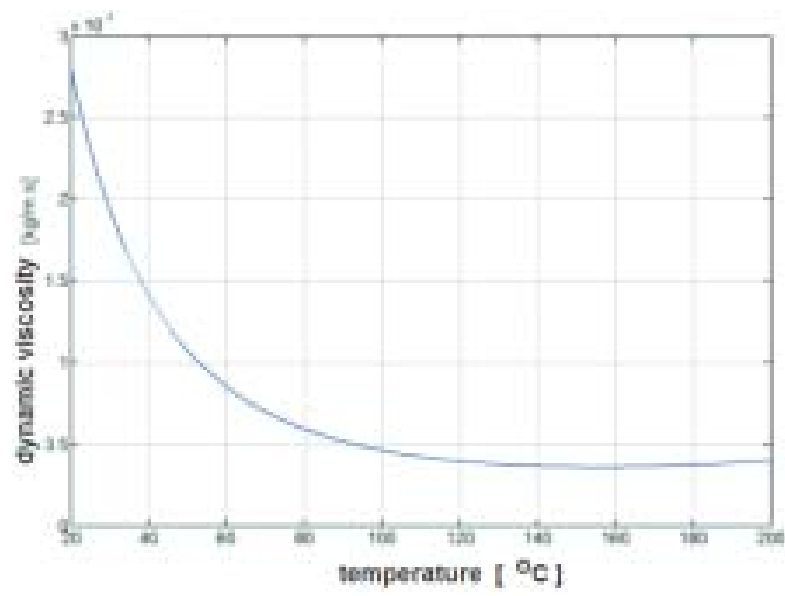

Graph 2. Dynamic viscosity

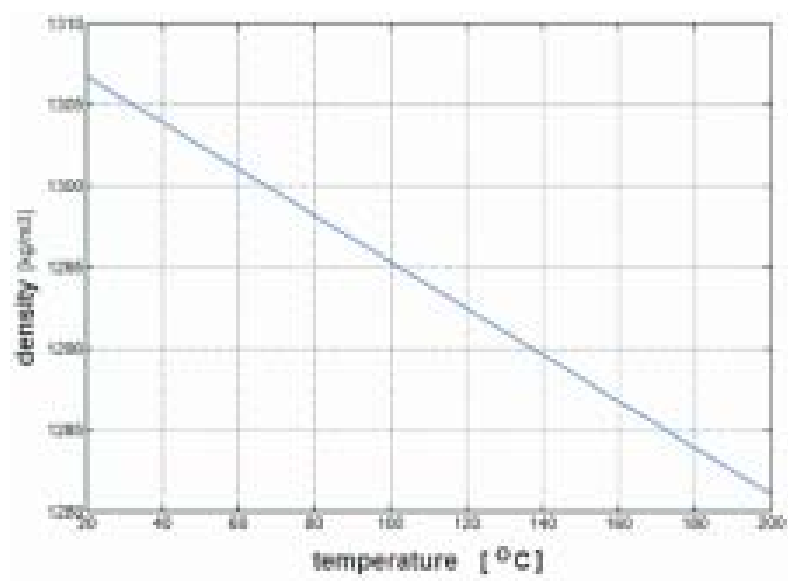

Graph 3 Density of coolant

- Geometry of the combustion engine cylinder generated in the ANSYS software.

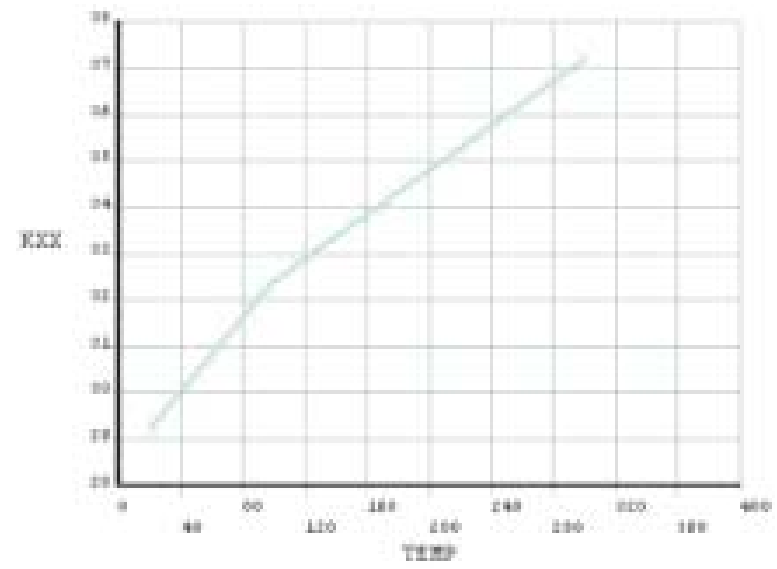

Fig. 3 Dependence of thermal conductivity coefficient $\lambda$ on temperature

- Boundary conditions.

- Coordinates of geometric keypoints.

- Material characteristics.

- Thermal analysis of the cylinder.

- The final elements network.

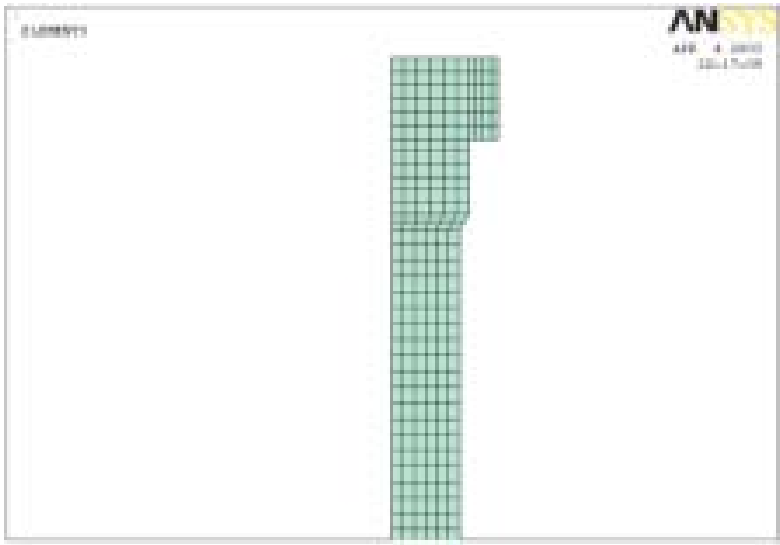

Fig. 4 Mesh of the model in ANSYS.

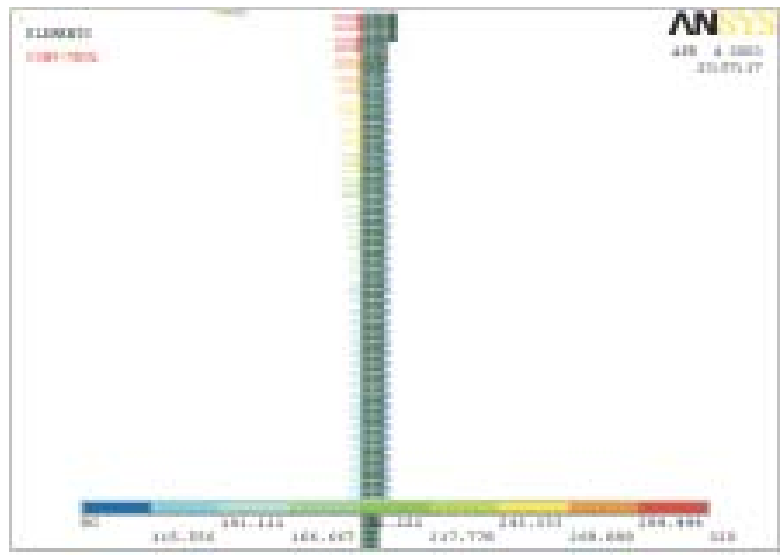

Fig. 5 Applied thermal loading in $C^{\circ}$.

12 - KOMUNIKÁCIE / COMMUNICATIONS 2/2006 
KaMNIIKCOCle

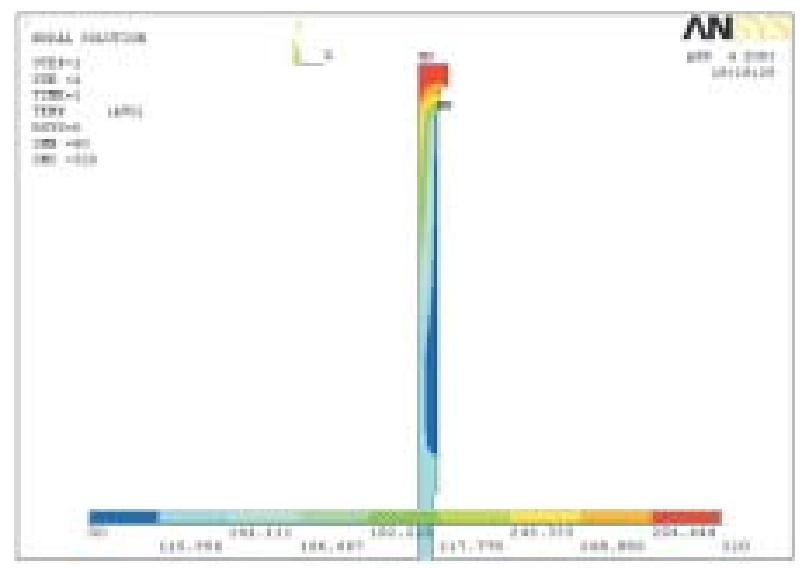

Fig. 6 Results of heat transfer in $C^{\circ}$

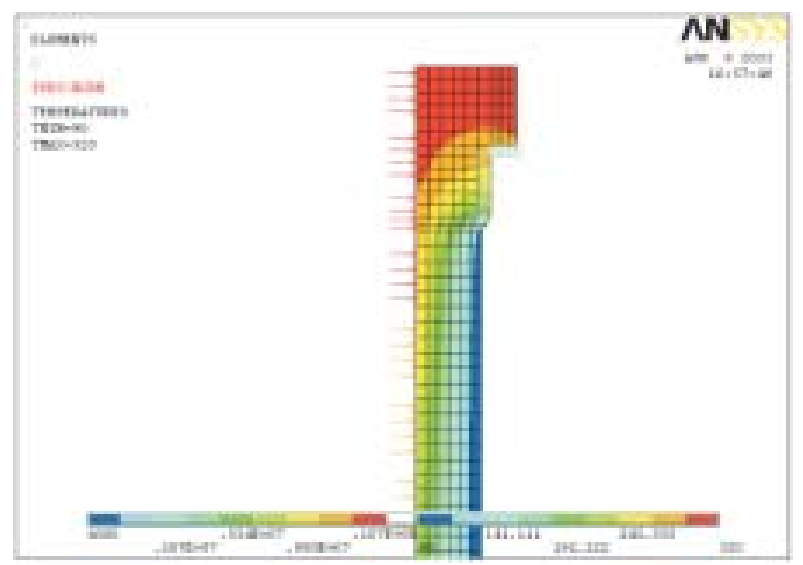

Fig. 8 Graph of pressure

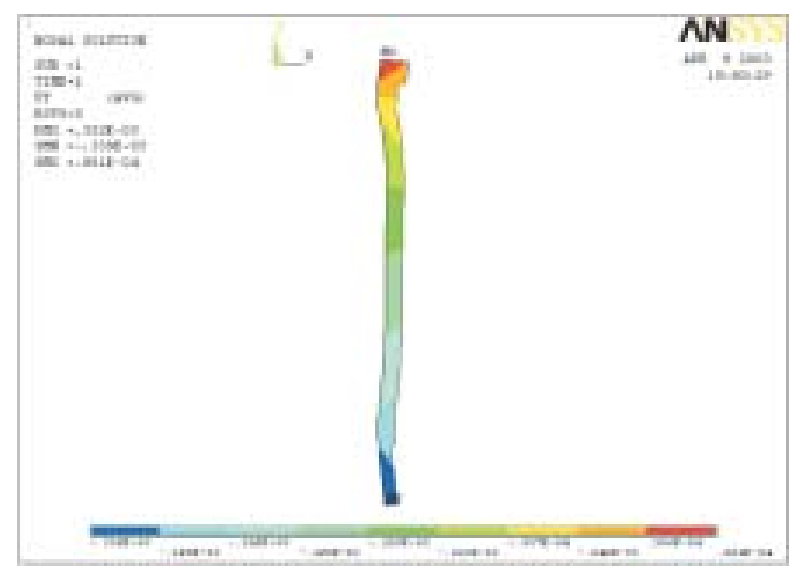

Fig. 10 Graph of displacements in direction (displacements are in metres)

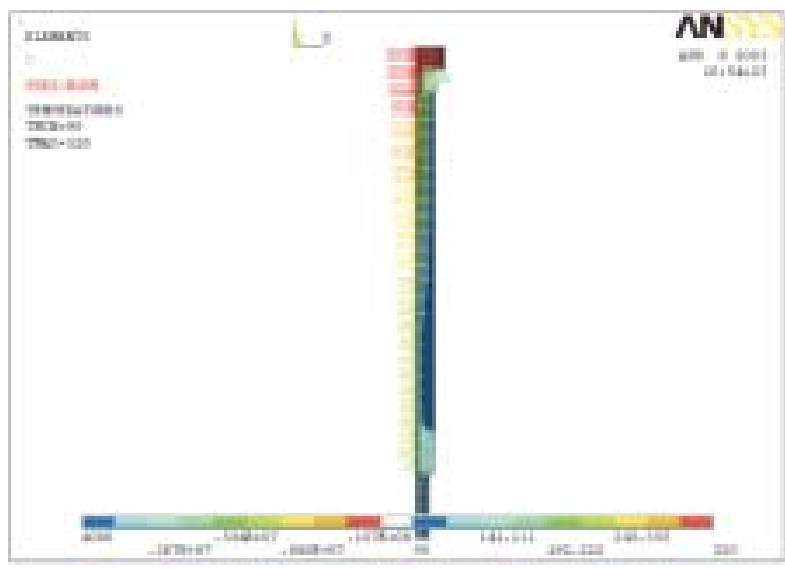

Fig. 7 Graph of pressure loading (from either side).

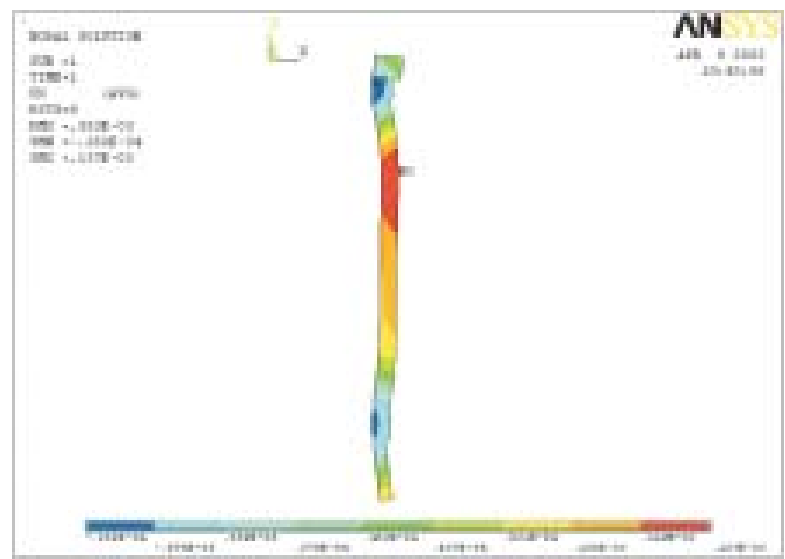

Fig. 9 Graph of displacements in the axis direction (displacements in metres) and temperatureloadings

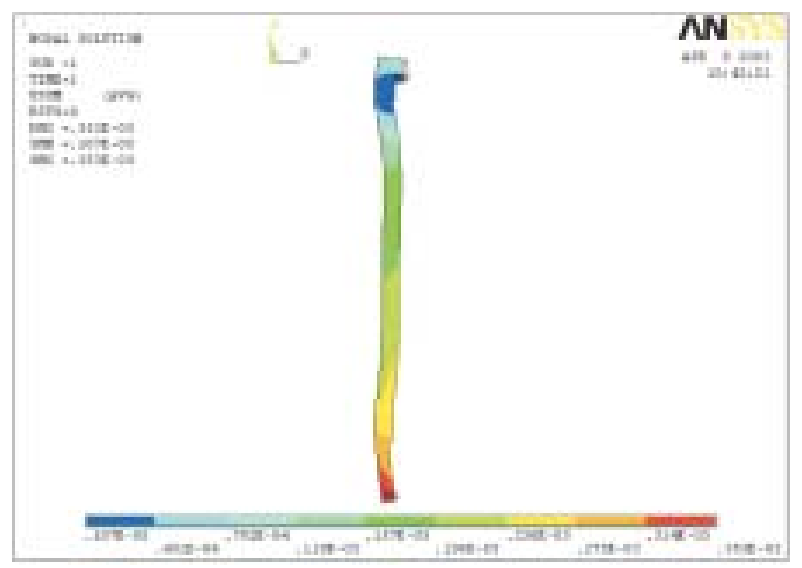

Fig. 11 Graph of full displacement of y-axis (displacements are in meters) 


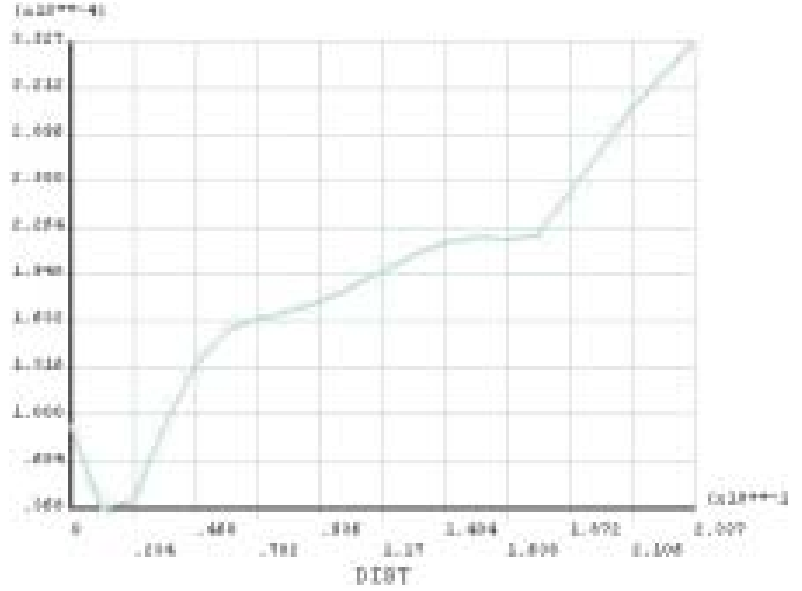

Fig. 12 Graph of full displacement dependences [m] (horizontal axis - cylinder length, vertical axis - full displacement)

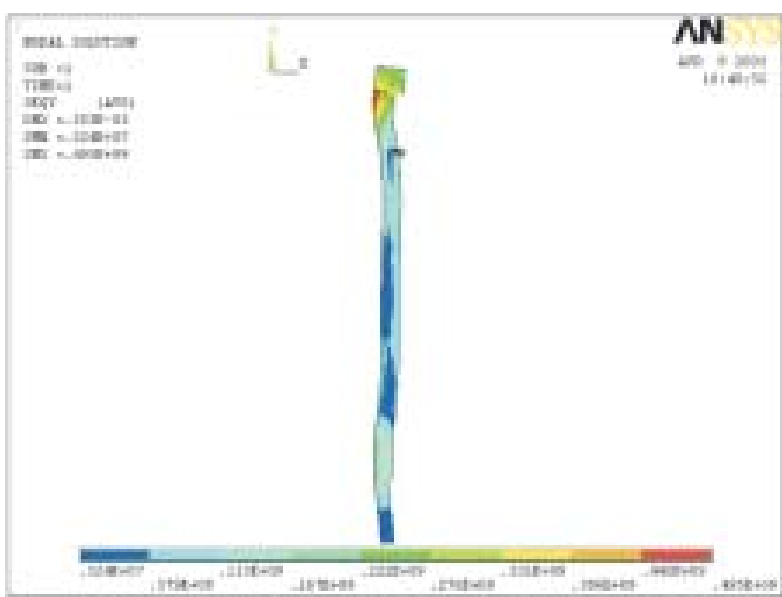

Figs. 13 Graph of stress distribution (Pa)

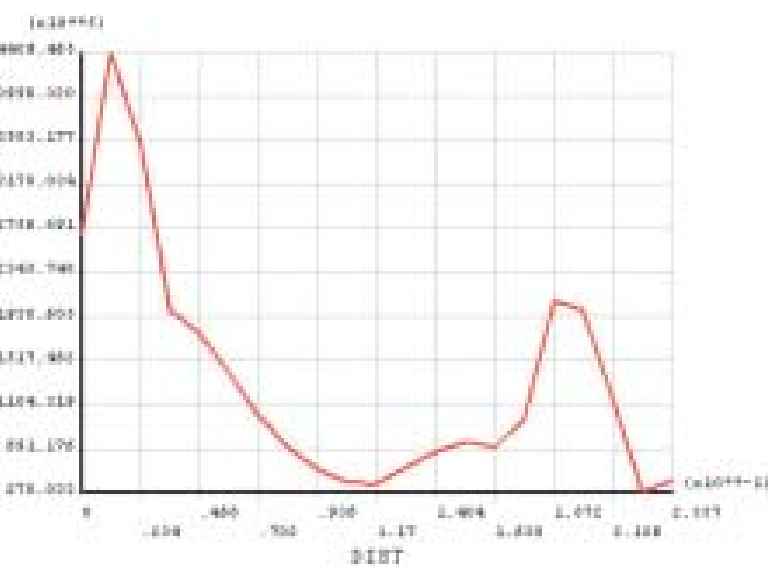

Fig. 15 Graph of stress dependence on the length (horizontal axis - cylinder length $[\mathrm{m}]$, vertical axis - stress [Pa])

From the results of the computation it was found out the the liner was loaded mainly in the upper part some $22 \mathrm{~mm}$ from the head by a relatively high stress of $445 \mathrm{MPa}$. The displacements can be considered insignificant mainly due to their position (in the $\mathrm{y}$-axis direction in the liner top and in the $\mathrm{x}$-axis direction in the upper quarter of the liner.

Modelling and simulation of coolant flow and energetic flows.

A mathematical model for flow analysis

The analysis is based on a mathematical model for turbulent flow of "renormalized groups type - RNG $k-\varepsilon$ - turbulent model". A renormalized procedure applied in turbulence lies in a gradual elimination of small turbulences. Simultaneously, equations of motion (Navier - Stokes equations) are transformed in such a way that turbulent viscosity, forces and nonlinear members are modified. Supposing that the turbulences are related to dissipation $\varepsilon$, then, 
Mass flow rate and temperatures.

Tab. 1

\begin{tabular}{|c|c|c|}
\hline $\begin{array}{c}\text { Mass flow rate } \\
\text { from outlet }\left[\mathrm{kg} \cdot \mathrm{s}^{-1}\right]\end{array}$ & $\begin{array}{c}\text { Mass flow rate round } \\
\text { cylinders }\left[\mathrm{kg} . \mathrm{s}^{-1}\right]\end{array}$ & $\begin{array}{c}\text { temperature on outlet } \\
\text { from cylinders }[\mathrm{K}]\end{array}$ \\
\cline { 1 - 1 } outletV1a $=0.096$ & $m_{\mathrm{w} 1}=0.233$ & $T_{v c h 1}=370.97$ \\
\cline { 1 - 1 } outletV1b $=0.137$ & $m_{w 2}=0.237$ & $T_{v c h 2}=369.12$ \\
\cline { 1 - 1 } outletV2a $=0.098$ & \multirow{2}{*}{$m_{w 3}=0.260$} & $T_{v c h 3}=368.21$ \\
\cline { 1 - 1 } outletV2b $=0.139$ & \multirow{2}{*}{ outletV3a $=0.105$} & $T_{v c h 4}=361.41$ \\
\cline { 1 - 1 } outletV3b $=0.155$ & $m_{w 4}=0.279$ & \\
\cline { 1 - 2 } outletV4a $=0.0984$ & & \\
\cline { 1 - 1 } outletV4b $=0.181$ & &
\end{tabular}

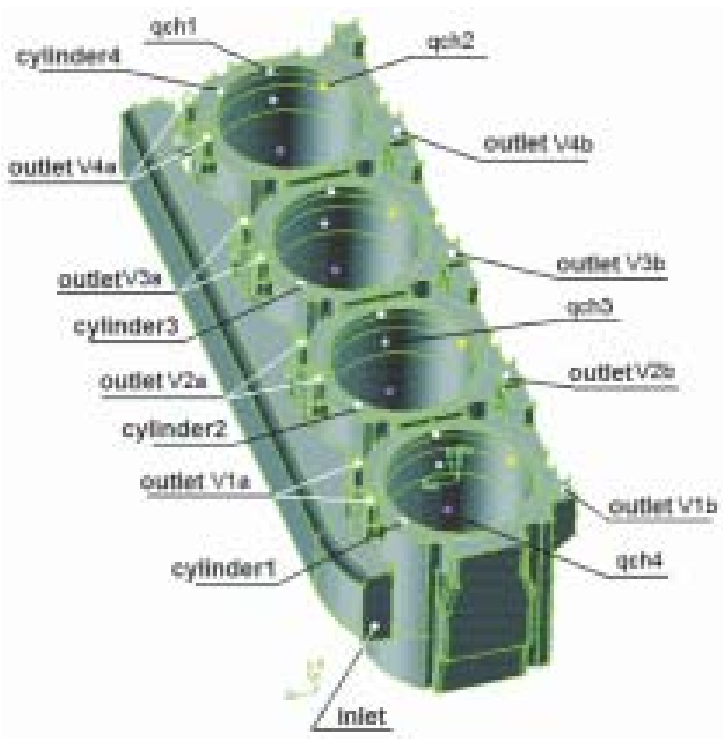

Fig. 17 Specification of boundary conditions

the turbulent viscosity $\mu_{\mathrm{i}}$ depends on a degree of turbulences and the RNG method constructs this viscosity with the help of iterative elimination of narrow bands of wave numbers. The following equation is used for the iterative process:

$$
\frac{d \mu_{e f f}}{d l}=\frac{A_{l} \varepsilon l^{3}}{\mu(l)^{2}} .
$$

The averaged RNG model derived by a statistical method has formally the same shape as the classical $k-\varepsilon$ model. The equation for transfer of momentum has the form:

$$
\begin{aligned}
& \frac{\partial}{\partial t}\left(\rho \bar{u}_{i}\right)+\frac{\partial}{\partial x_{j}}\left(\rho \bar{u}_{i} \bar{u}_{j}\right)=\frac{\partial}{\partial x_{j}}\left[\mu_{\text {eff }}\left(\frac{\partial \bar{u}_{i}}{\partial x_{j}}+\frac{\partial \bar{u}_{j}}{\partial x_{i}}\right)-\right. \\
& \left.-\left(\frac{2}{3} \mu_{\text {eff }} \frac{\partial \bar{u}_{i}}{\partial x_{i}}\right)\right]-\frac{\partial \bar{p}}{\partial x_{i}}+\rho g_{i}+F_{i},
\end{aligned}
$$

and, consequently, transport equations are used:

$$
\frac{\partial}{\partial t}(\rho k)+\frac{\partial}{\partial x_{j}}\left(\rho \pi_{j} k\right)=\frac{\partial}{\partial x_{j}}\left(\alpha k \mu_{e f f} \frac{\partial k}{\partial x_{j}}\right)+\mu_{t} S^{2}-\rho \varepsilon
$$

$$
\begin{aligned}
& \frac{\partial}{\partial t}(\rho \varepsilon)+\frac{\partial}{\partial x_{j}}\left(\rho \mu_{j} \varepsilon\right)=\frac{\partial}{\partial x_{j}}\left(\alpha_{\varepsilon} \mu_{\text {eff }} \frac{\partial \varepsilon}{\partial x_{j}}\right)+ \\
& +C_{1 \varepsilon} \frac{\varepsilon}{k} \mu_{t} S^{2}-C_{2 \varepsilon} \rho \frac{\varepsilon^{2}}{k}-R
\end{aligned}
$$

\begin{tabular}{|c|c|c|}
\hline & $\begin{array}{l}\text { Data computed by } \\
\text { model }\end{array}$ & $\begin{array}{l}\text { Data measured } \\
\text { experimentally }\end{array}$ \\
\hline $\begin{array}{l}\text { Mass flow through } \\
\text { block }\left[\mathrm{kg} \cdot \mathrm{s}^{-1}\right]\end{array}$ & $m_{w}=\sum_{i=1}^{4} m_{w i}=1.01$ & $m_{w}=1.01$ \\
\hline $\begin{array}{c}\text { Average mising } \\
\text { temperature leaving } \\
\text { block }[\mathrm{K}]\end{array}$ & $T_{v c h}=\frac{\sum_{i=1}^{4} T_{v c h i}}{4}=367.17$ & $T_{v c h}=367.24$ \\
\hline $\begin{array}{l}\text { Total thermal flow } \\
\text { to the cooling system } \\
{[\mathrm{W}]}\end{array}$ & $\begin{array}{l}Q_{c h}=M_{c h} \cdot c \cdot \\
\left(T_{v c h}-T_{v y c h}\right)= \\
\quad=41274.66\end{array}$ & $\begin{array}{c}Q_{c h}=M_{c h} \cdot c \cdot \\
\cdot\left(T_{v c h}-T_{v y c h}\right)= \\
\quad=41571.6\end{array}$ \\
\hline
\end{tabular}

For more details see [4].

Computed and measured data

Tab. 2

Thermal flow from inserted cylinder.

Tab. 3

\begin{tabular}{|l|c|}
\hline \multicolumn{2}{|l|}{ Thermal flow from inserted cylinder $Q_{c h i}[\mathrm{~W}]$} \\
\hline$Q_{c h 1}$ & 13240.5 \\
\hline$Q_{c h 2}$ & 11626.3 \\
\hline$Q_{c h 3}$ & 11760.8 \\
\hline$Q_{c h 4}$ & 4652.0 \\
\hline Total thermal flow into coolant $Q_{c h}=\sum_{i=1}^{4} Q_{c h i}$ & 41279.6 \\
\hline
\end{tabular}

Specification of places for measurement. Design of measure chain - sensors, transmitters.

The quality of the actual evaporation process is influenced by a constructional arrangement of the non-conventional cooling circuit of the combustion engine, pressure and temperature conditions under which the evaporation is assessed and concentration of alternative coolant. The cooling potential of atmospheric circuit is examined. Temperature conditions are defined by the boiling point of non-conventional coolant.

When compared with the former cooling system designed for tractor or automobile engines, for the non-conventional cooling system the following items can be defined:

Mass equation of the non-conventional system:

$$
M_{c h}=m_{c h l}+m_{c h d}
$$

Energetic equation of the non-conventional system (disredarding other thermal losses): 


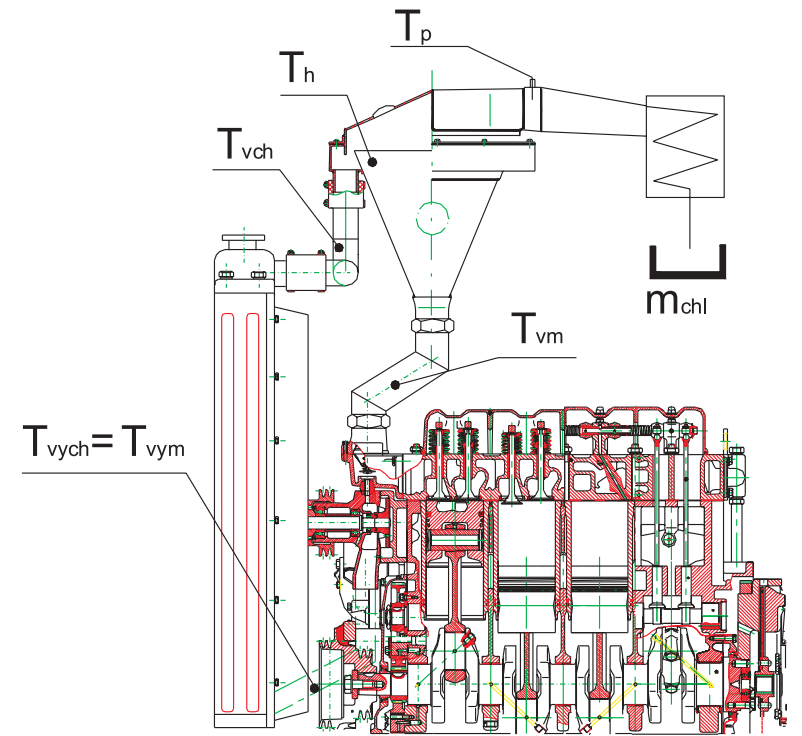

Fig. $18 a m_{c h l}$ - coolant mass flow, $T_{v m}$ - temperature on engine outlet, $T_{p}$ - vapour temperature, $T_{h}$ - surface temperature in evaporator,

$T_{v c h}$ - temperature of lean solution leaving the evaporator and entering the radiator, $T_{v y c h}$ and $T_{v y m}$ - temperature entering the combustion engine.

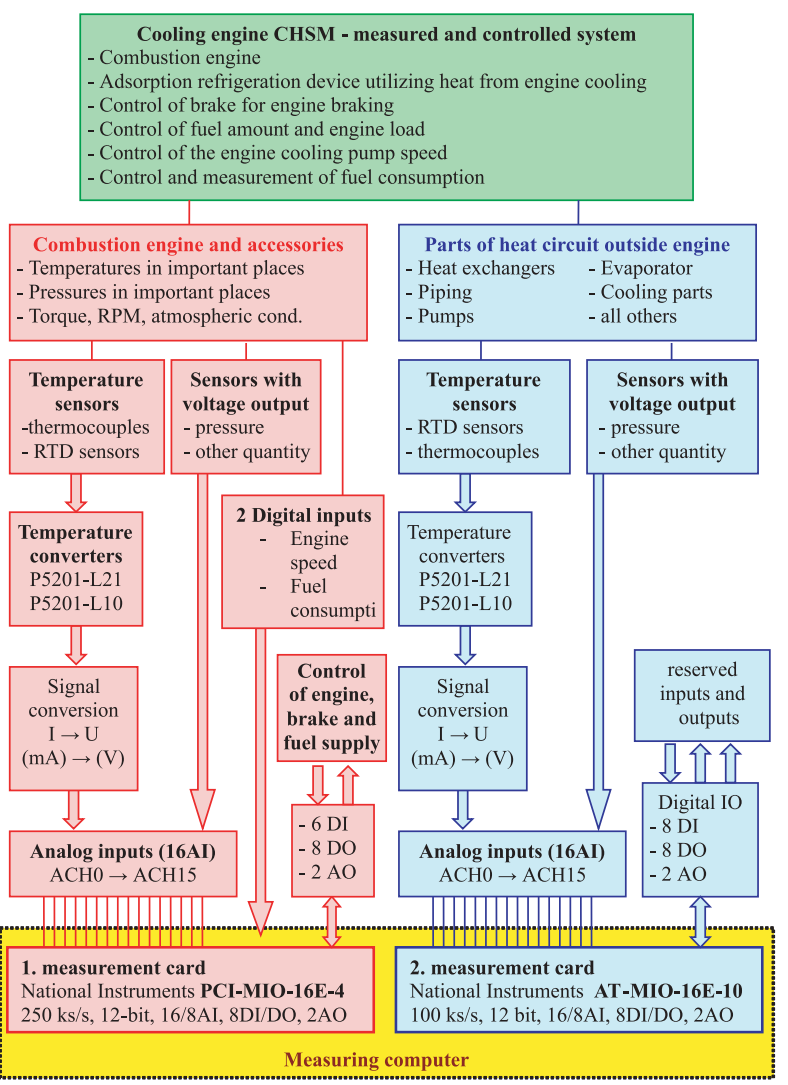

Fig. $18 b$ Scheme of the measurement system of CHSM cooling engine

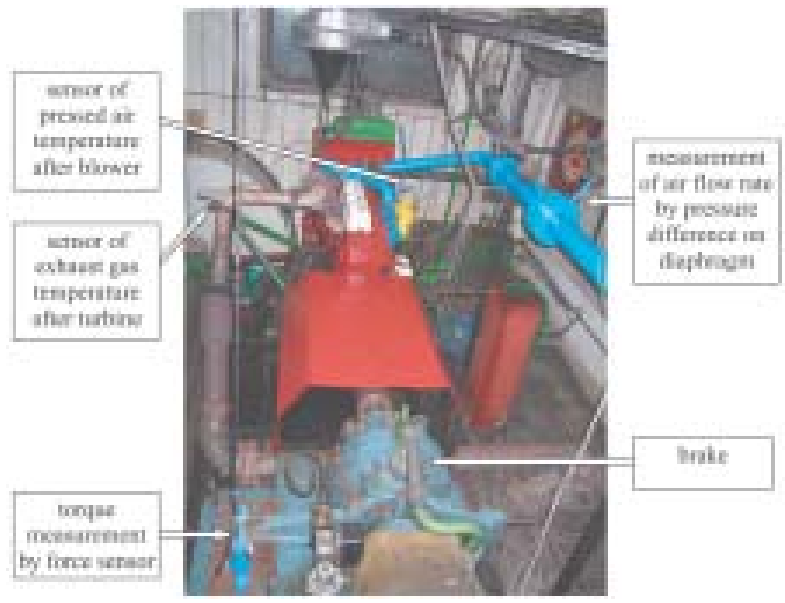

Fig. 18c Placement of selected measurement sensors

$Q_{c h}=Q_{v y ́ p}+Q_{o c h}$

Evaporation efficiency:

$$
\begin{aligned}
& U_{t k}=\frac{Q_{v y ́ p}}{Q_{c h}}=1-\frac{Q_{o c h}}{Q_{c h}}=1-\frac{m_{c h d} \cdot c \cdot\left(T_{v c h}-T_{v y c h}\right)}{M_{c h} \cdot c_{r}\left(T_{v m}-T_{v y m}\right)}= \\
& =1-\frac{m_{c h d} \cdot c \cdot \Delta T_{c h}}{M_{w} \cdot c_{r} \cdot \Delta T_{M}} \\
& U_{t k}=1-\frac{Q_{o c h}}{Q_{c h}}=1-\frac{\left(T_{v c h}-T_{v y c h}\right)}{\left(T_{v m}-T_{v y m}\right)}=1-\frac{\Delta T_{c h}}{\Delta T_{M}} .
\end{aligned}
$$

Within further reconstruction (reconstruction - adjustment of temperature sensors, insulation of the evaporation container) the $Q_{o c h}<Q_{c h}$ states are modelled at the atmospheric pressure. When defining this state it is necessary to follow trends of chosen parameters (oil temperature, exhaust gases temperature, flow through the block, temperature of the liquid at entering or leaving the engine, temperatures in the evaporation container, torque, consumption), which might clarify the transport of heat from the combustion space to the surface in the evaporation container.

Consequently, it is possible to define the value of a reduced output number as:

$$
C O P_{R E D}=\frac{Q_{e} \cdot \eta_{e l}+Q_{c h} \cdot U_{t k}}{Q_{p}} .
$$

If we are able - when realizing the complex cooling system in the required conditions - to define the state $\Delta T_{c h}=0$ under suitable temperature and heat conditions on the combustion engine, then $U_{t k}=1$. Then, it follows that we are able to maximally utilize after-expansion exergy in the cooling system and that we are also able to transform it into evaporation heat required for defining the cooling output of the absorptive unit.

Points for temperature measurement. 


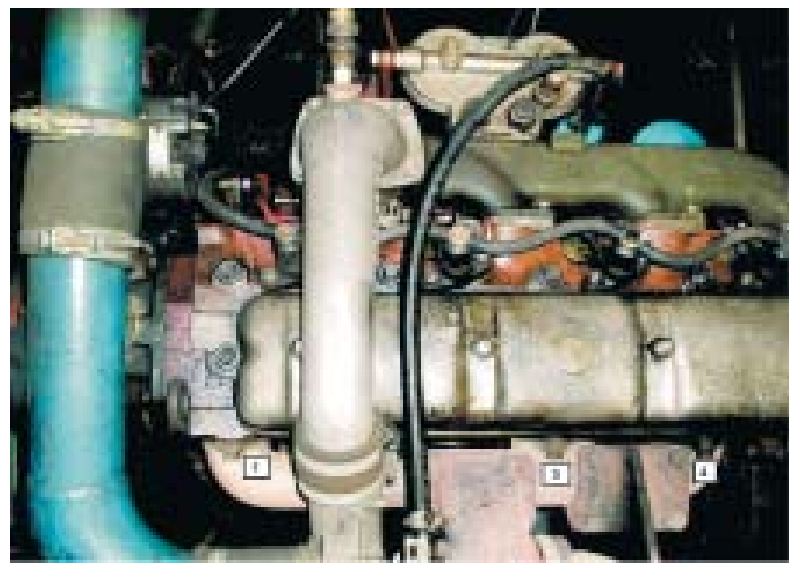

Fig. 19 Top view

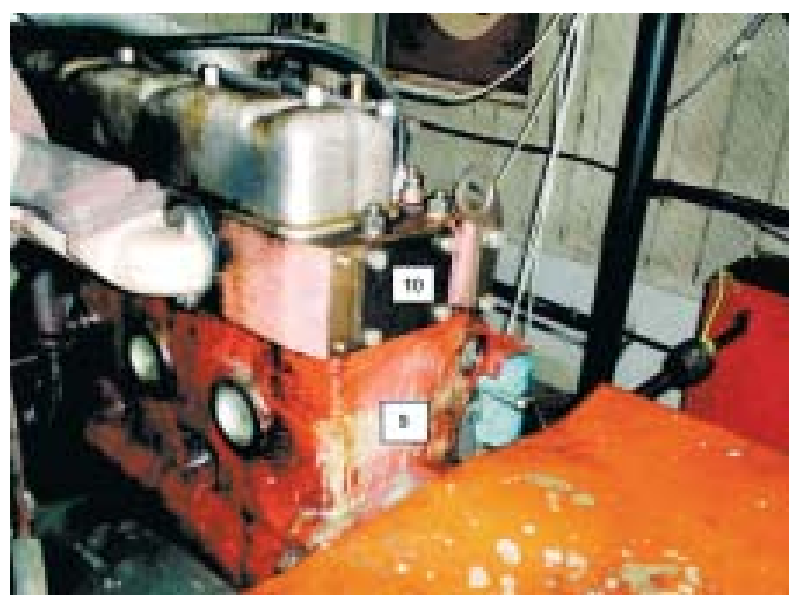

Fig. 21 View of the engine back

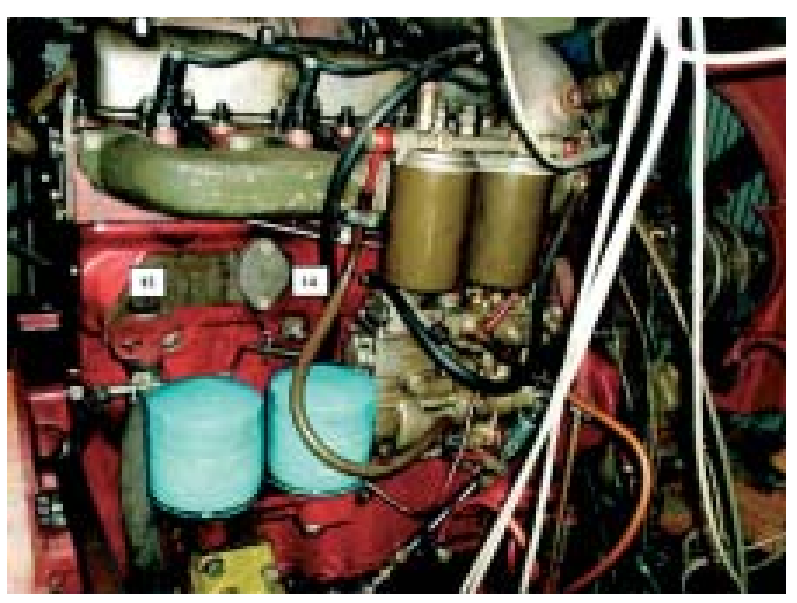

Fig. 23 View 2, view of the injection pump.

Graphs of measured values (graph 4 and graph 5).

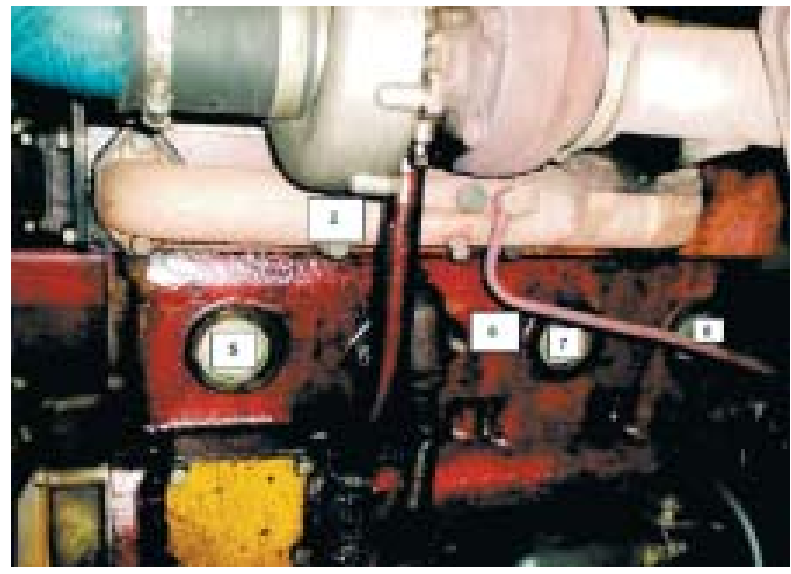

Fig. 20 View of the turbocharger side

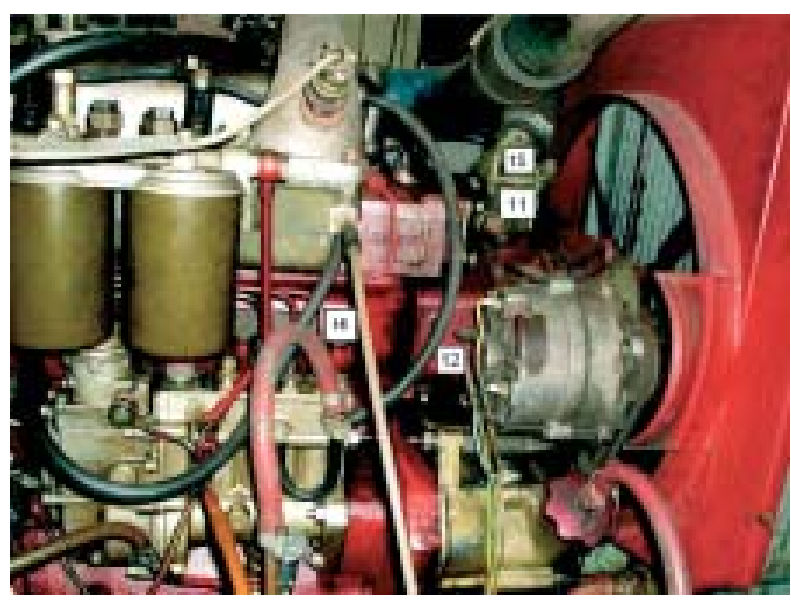

Fig. 22 View 1, the injection pump

The year 2004

The following activities were carried out:

1. theoretical analysis and mathematical modelling

- Drawing documentation for forced adjustments of the engine and test stand.

- Checking and connecting the sensors for new tests, i.e. observation of the evaporation process, temperature states at intensification of evaporation under atmospheric pressure and consequently at underpressure.

- Detailed topography of cavities of the engine cooling jacket, designed simplified virtual model of the engine cooling jacket, realistic meshing.

- Modelling - meshing of the cavities of the engine cooling jacket - for calculation.

- Solution of boundary tasks and conditions for the modelling of heat flows in the block.

- Checking calculations and simulation of influence of changes in the boundary conditions.

- Preliminary calculation (thermal balance) of quantities characterizing the state of coolant in particular places of the energetic circuit with the cooling combustion engine. 


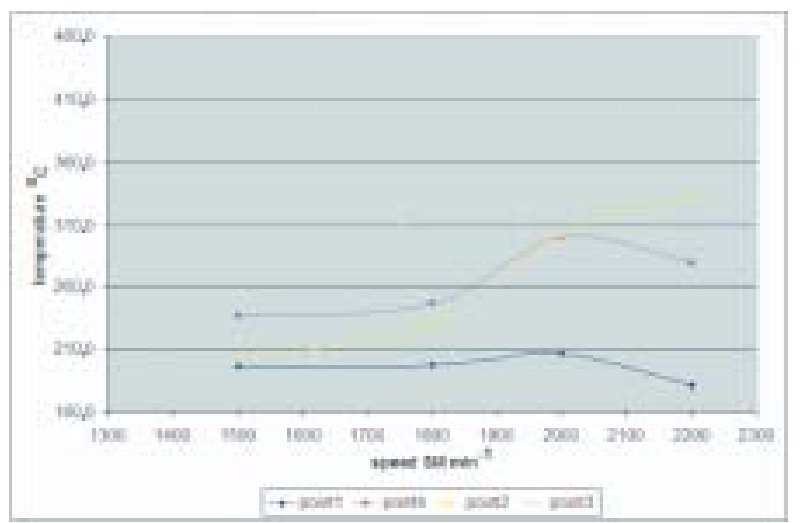

Graph 4(left) Change of temperature for revolutions in defined points.

\section{2. experiments}

- Measurements of surface temperatures of the engine - assessment.

- Dismantling and assembly of the engine for the purpose of topography of the cooling jacket (of real cavities).

- Tests of the original engine - with an alternative coolant $(\mathrm{LiBr})$.

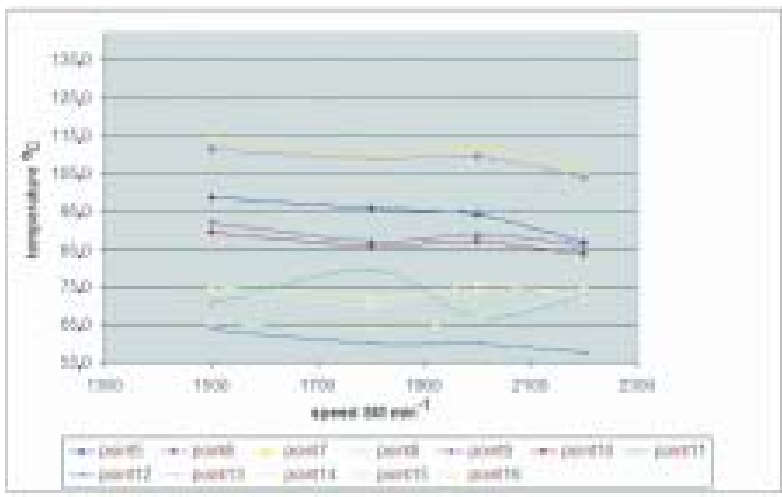

Graph 5(right) Change of temperaturefor revolutions in defined points.

- Tests of the engine with an adjusted cooling system with the evaporator to define the output reduced number.

- The arrangement of the test stand and its control with the focus on automation of tests of the engine with a modified cooling circuit with an external pump in order to verify the results from the virtual modelling.
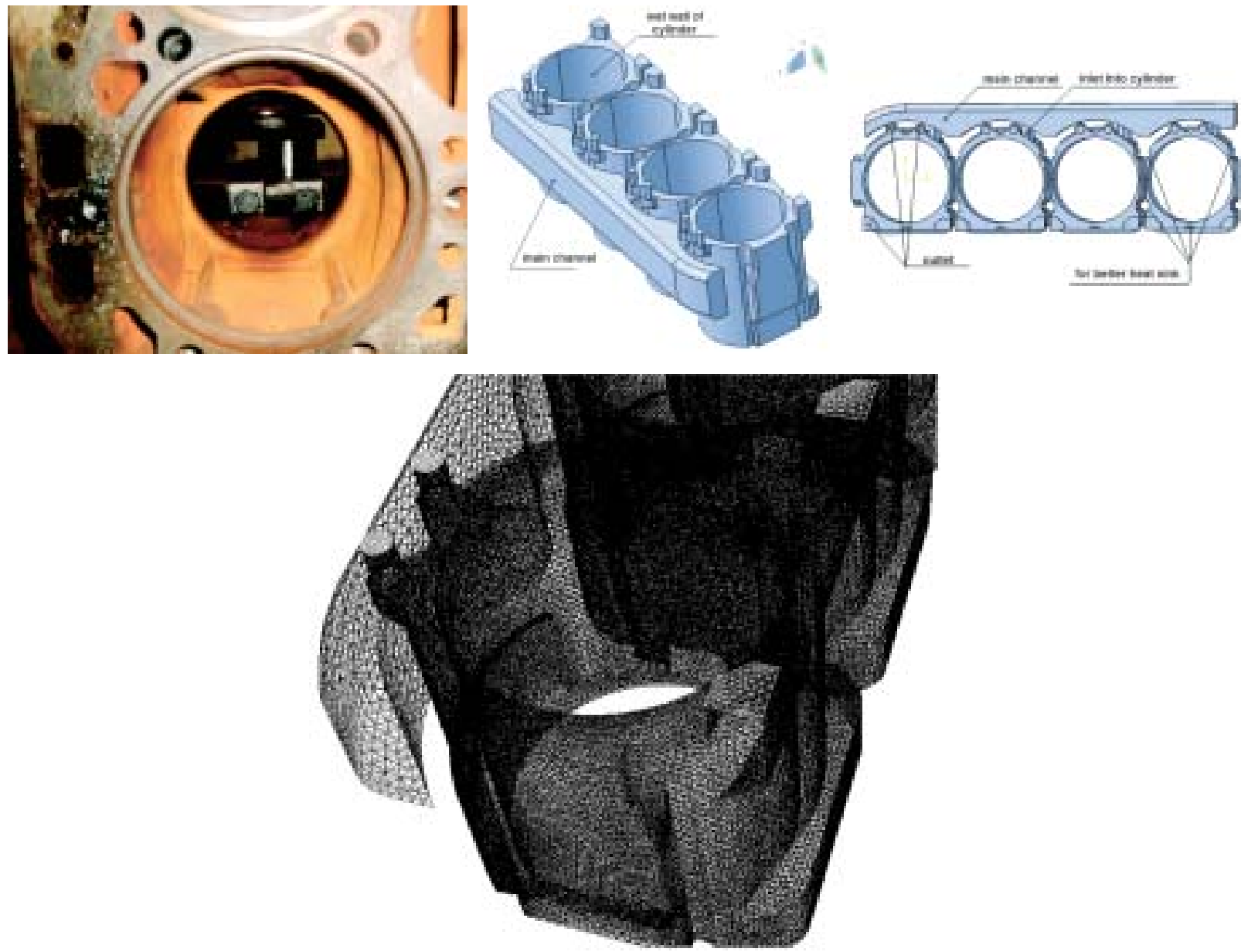

Fig. 24 Cavities of cooling jacket - real, virtual model, mesh 
keMNlkocle

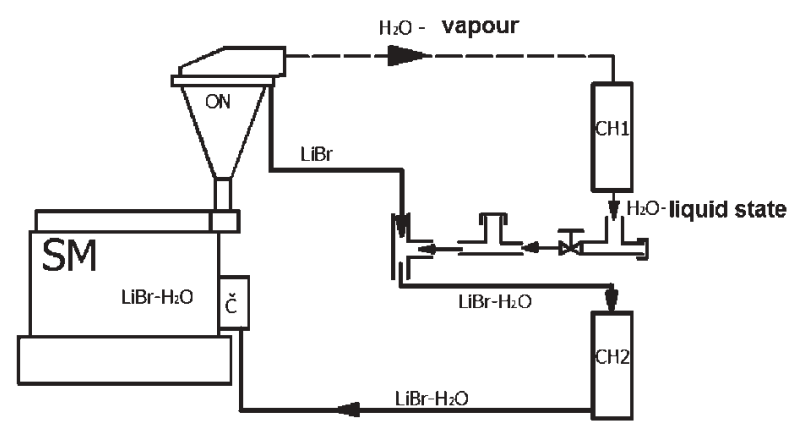

Fig. 25 (left) Assembly of atmospheric test stand.

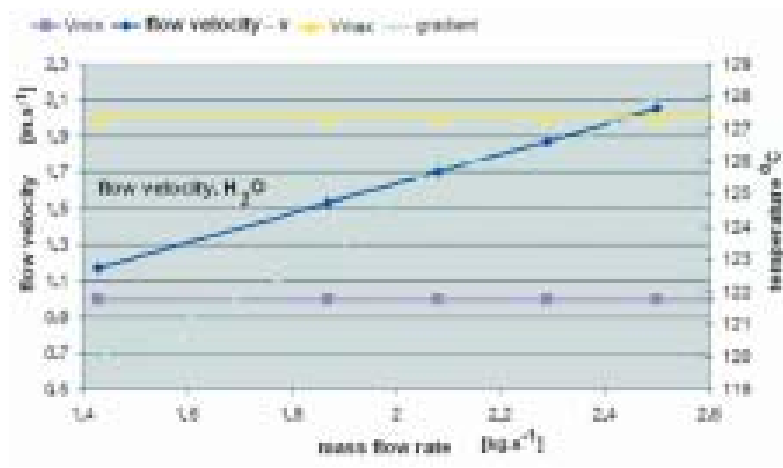

Graph 7(left) $v_{\min }$ - min. value of interval recommended for velocity of flow in the engine block, $v_{\max }-$ max. value of interval recommended for velocity of flow in the engine block.

The resultant point of the cooperation of the ICE with the absorptive cooling system.

All the investigated parameters were recorded and assessed with a computer programme.

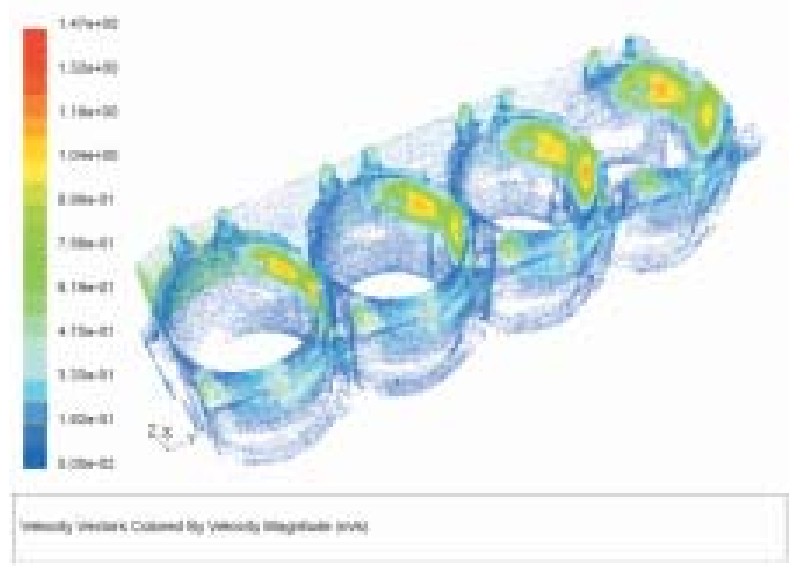

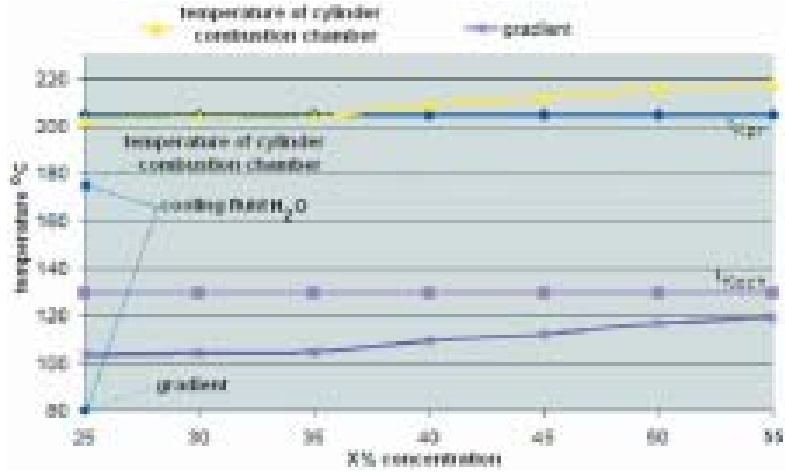

Graph 6 (right) $t_{K p r}$ - criterion of critical average temperature of overheating, $t_{\text {Koch }}$ - criterion of critical average temperature of cooling.

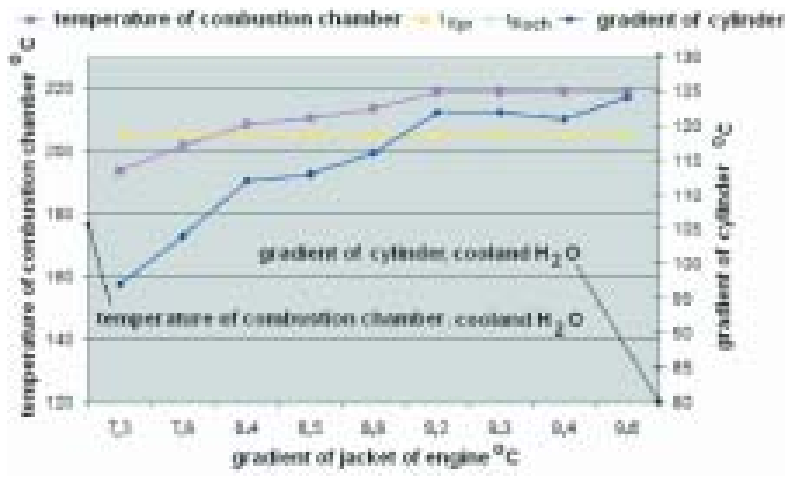

Graph 8 (right) Course of observed temperatures on gradient under the constant condition of output temperature from the ICE block.

Alternatives of the cooling system arrangement

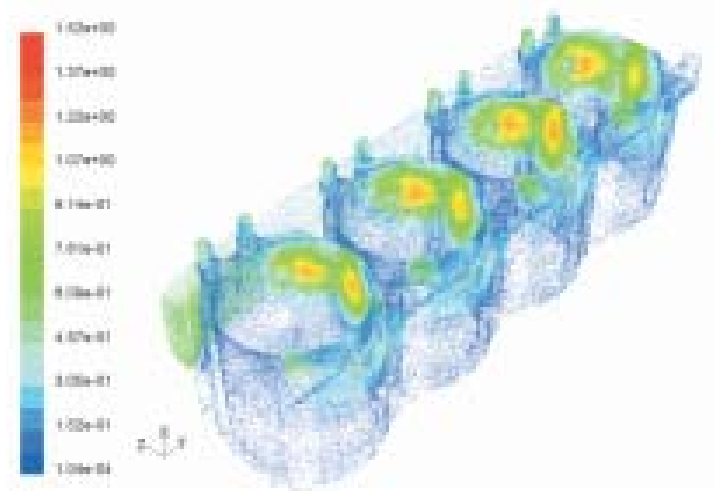

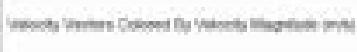

Fig. 26 Velocity field of flow (original coolant on the left, alternative coolant on the right) 


\section{KaMNIKCOCle}
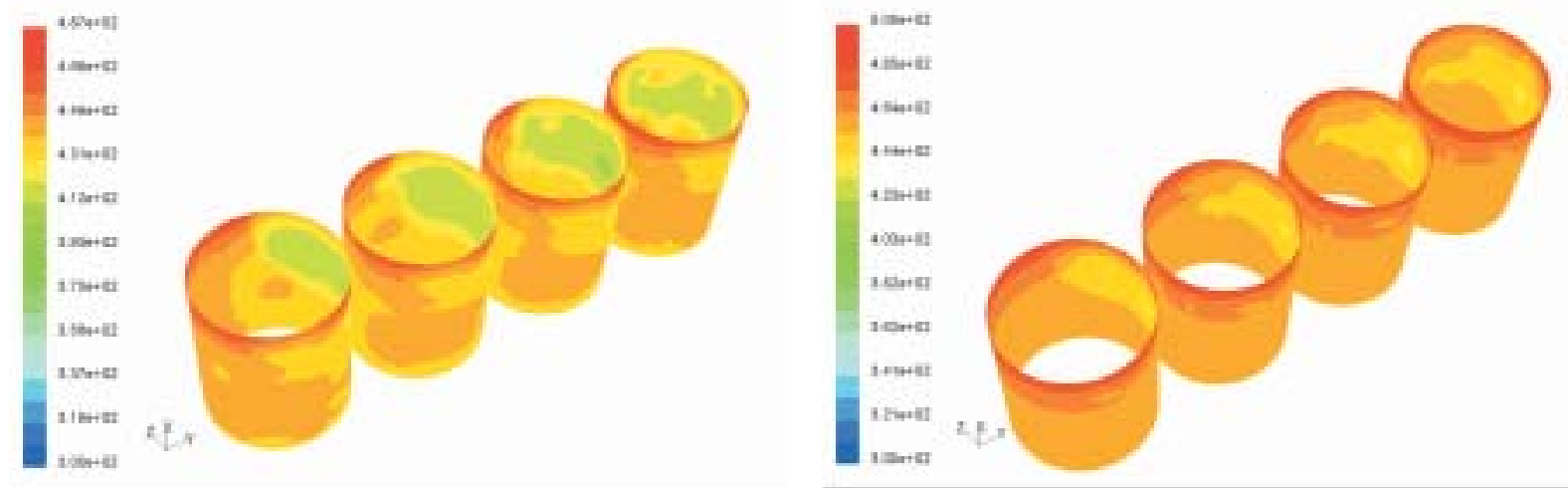

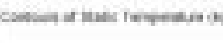

Comount Bhes Temoment

Fig. 27 Temperature fields (original coolant on the left, alternative coolant on the right)
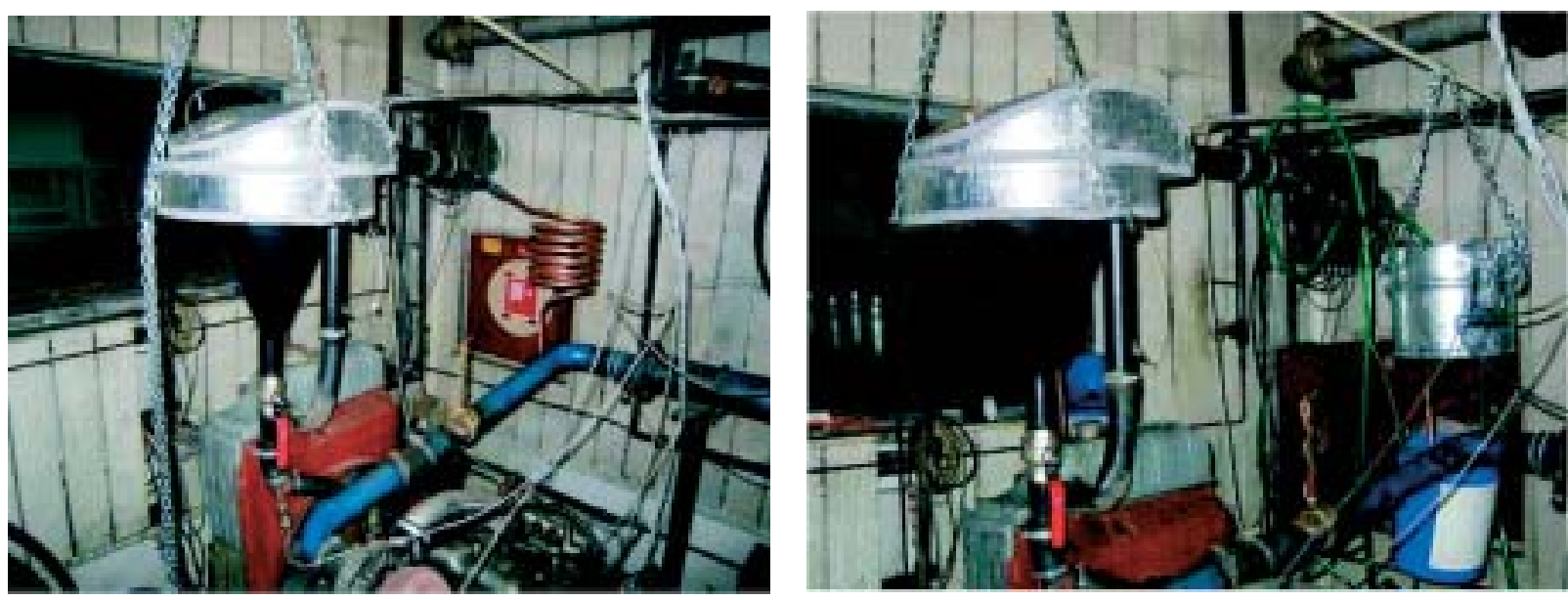

Fig. 28 A alternative - left: view of non-cooled copper spiral, right: view of cooled copper spiral

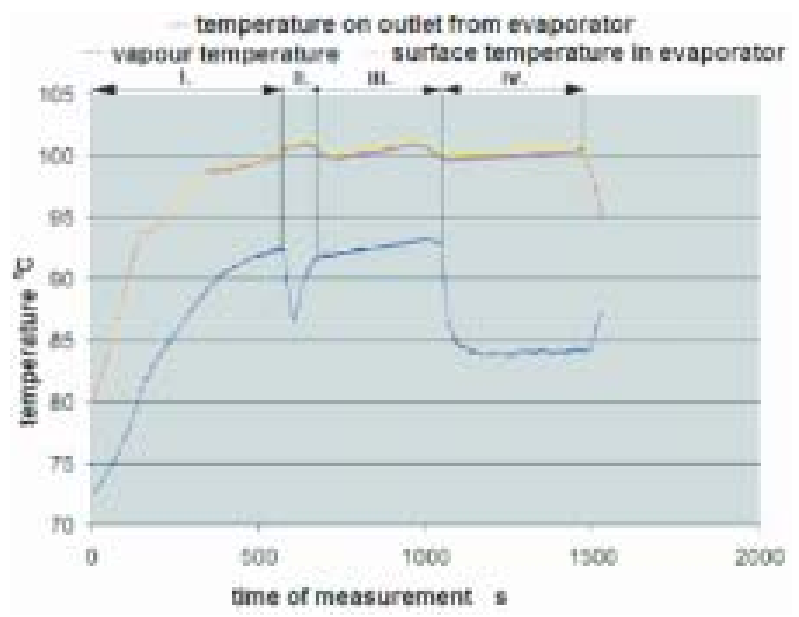

Graph 9 Measurements for A alternative

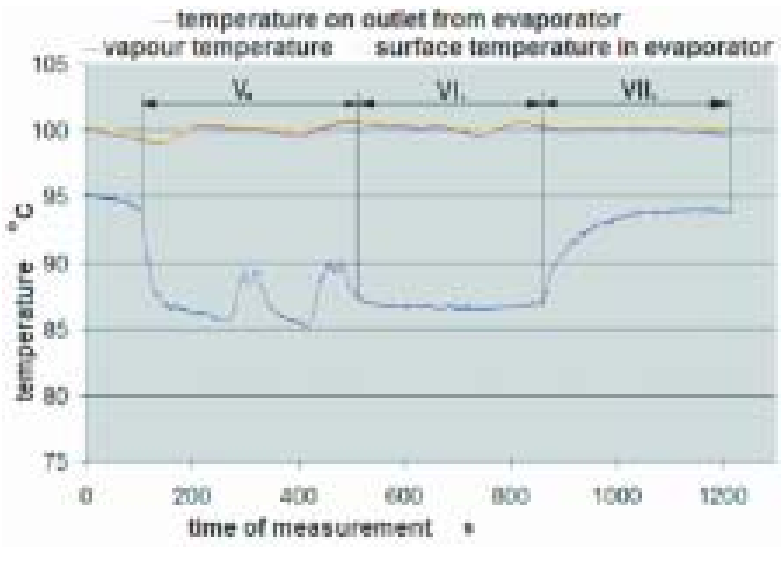

Graph 10 Measurements for B alternative 


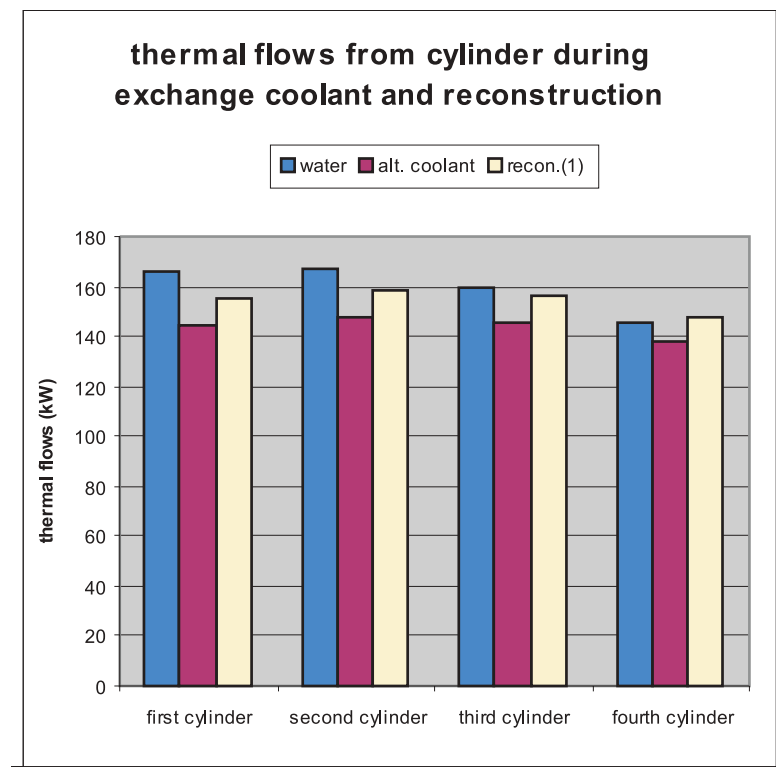

Graph 11. Results of modelling of exergy flow

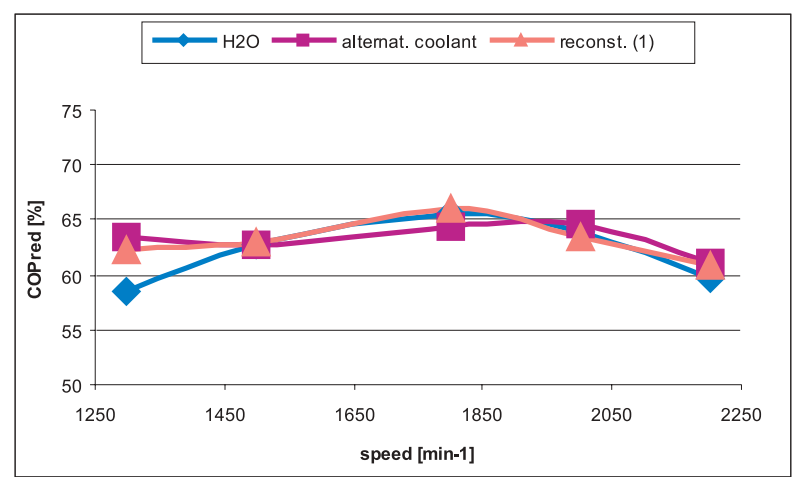

Graph 12 Performance coefficient

The year 2005

The following activities were carried out:

1. experiments

- Measurements taken on the engine with the adjusted cooling circuit with the external circulation pump with the aim of assessing real flows of coolant for further virtual modelling.

2. alternatives of solution, assessment and final reviewing procedure.

- Heat and energetic losses for different flows of coolant and constant revolutions of the engine.

- Evaluation of the project main objective.

- Final opinions of reviewers.

Quantitative assessment of publications written during the project solution:

Publications in foreign and domestic journals

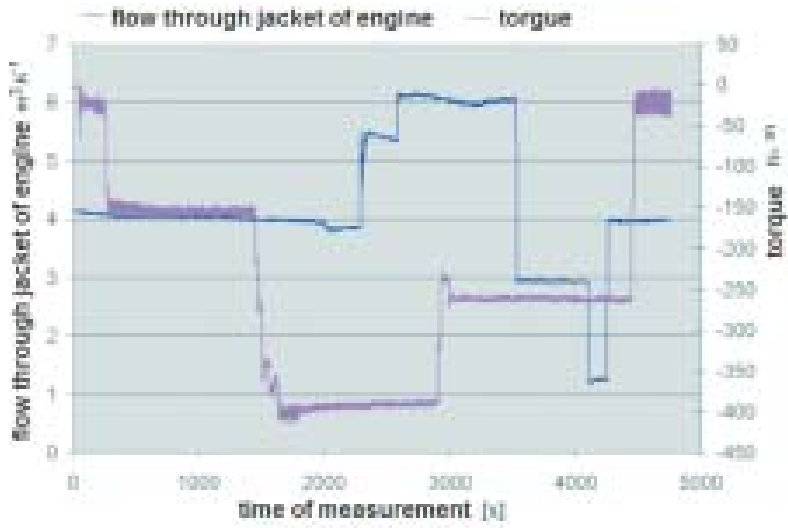

Graph 13(left) Changes in flow through the ICE block and engine loading (that is why the values are negative)

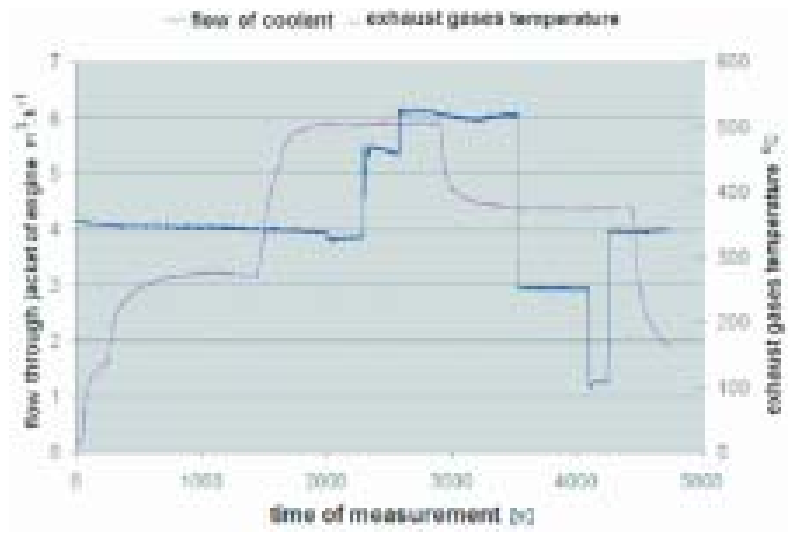

Graph 14(right) Changes in exhaust gases temperature and flow of coolant through the block

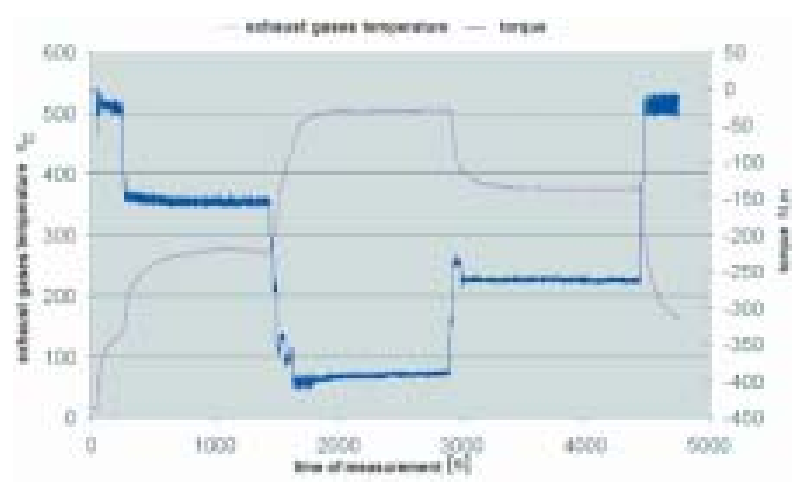

Graph 15(left) Changes in torque and and exhaust gases temperature

Scientific monographs

(also individual chapters) abroad

Number: 1

Scientific conferences (presentations, posters)

Number: 17

Doctoral dissertations and diploma theses 


\section{kOMNIILCe}

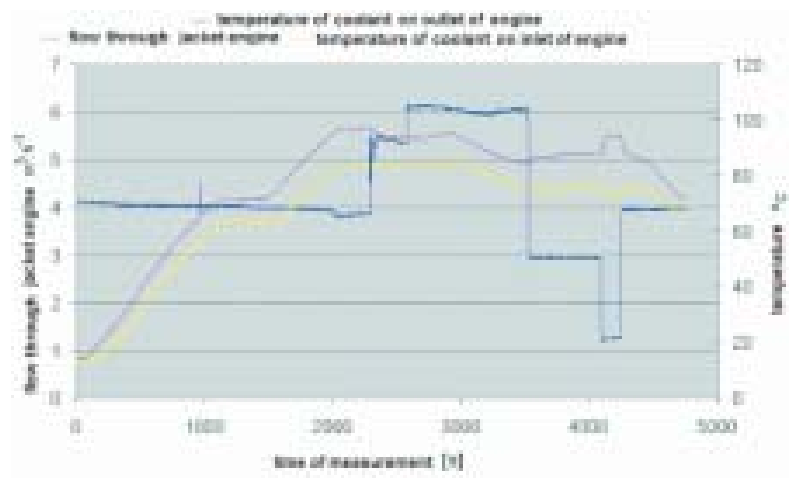

Graph16(right) Temperature changes in relation to the change of coolant flow

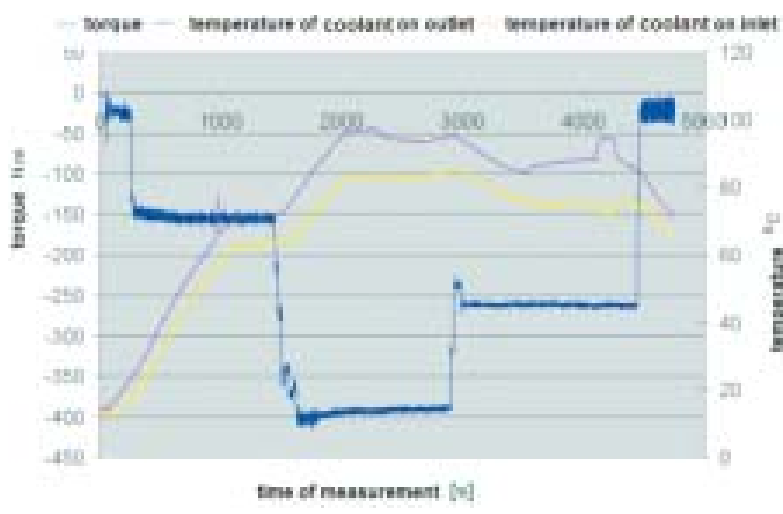

Graph 17(left) Temperature changes in relation to torque change

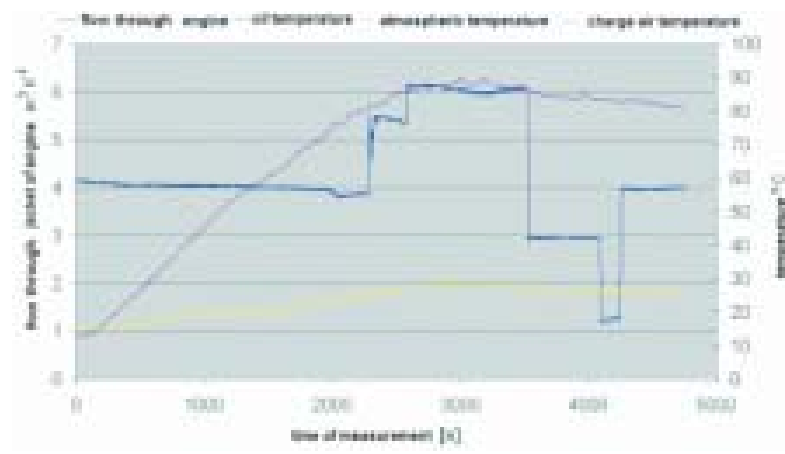

Graph 18(right) Changes in temperatures of oil and charge air

\section{Social benefits}

\section{Extension of existing knowledge}

The results of both theoretical solution and experiment were continuously published in journals and presented at conferences not only in the Slovak Republic but also abroad.

Aplication of new knowledge in educational materials of institutions of higher learning

Within the framework of the pedagogical process students of engineering and doctoral forms of study get acquainted with the results of theoretical solution and during laboratory practical activities and individual students activities (e.g. theses and dissertations) directly participate in the project solution.

Transfer of knowledge for consequent task solutions

On the basis of the results achieved within this project solution we submitted an application for another project "Non-conventional energetic unit with a cooling combustion engine". The project was approved by the Agency for Support of Science and Technology as APVT-20-018404. The project makes use of the results gathered from basic research, i. e. more effective utilization of fuel primary energy (in this specific case it is oil) by means of nonconventional principle of transfer of heat into cold by thermocompressions in the piston combustion engine (cooling combustion engine).

\section{Extension of scientific and technical know how}

The project solution confirmed the possibility of utilization of thermocompression in the classical piston combustion engine and thus contributed to the extension of the contemporary scientific and technical knowledge.

The paper is based on the final report on the project.

The contribution was created within the framework of the project Nr. APVT - 20 - 010302, which is supported by the Agency for Support of Science and Technology of the Slovak Republic. 